\title{
Analisis Potensi, Efektivitas Pemungutan Dan Kontribusi Pajak Hotel Terhadap Penerimaan Pajak Daerah Di Kabupaten Bandung
}

\author{
Deden Edwar Yokeu Bernardin ${ }^{1}$ \\ deden.eyb@gmail.com, Jurusan Akuntansi, Universitas BSI Bandung
}

Mega Muliawati Pertiwi

megamuliawati46@gmail.com, Jurusan Akuntansi, Universitas BSI Bandung

\begin{abstract}
ABSTRAK
Tujuan penelitian ini agar mengetahui seberapa besar pengaruh potensi, efektivitas dan kontribusi pajak hotel terhadap penerimaan pajak daerah di Kabupaten Bandung secara parsial dan simultan. Sumber data yang digunakan adalah data primer dan sekunder. Metode yang digunakan dalam penelitian ini adalah analisa deskriptif dan verifikatif. Penelitian ini dilakukan di Badan Keuangan Daerah Kabupaten Bandung. Data yang diambil adalah 10 tahun dari tahun 2008 sampai dengan tahun 2017. Teknik analisa yang dipakai yaitu analisa deskriptif verifikatif, Uji Asumsi Klasik, Koefisien Determinasi, Koefisien Korelasi Berganda dan Analisa Jalur. Hasil dari penelitian ini bahwa potensi pajak hotel memiliki pengaruh yang tidak signifikan terhadap penerimaan pajak daerah, hal tersebut menunjukkan bahwa besarnya potensi jika tidak tergali maksimal maka tidak berpengaruh pada penerimaan pajak daerah. Efektivitas pemungutan pajak hotel memiliki pengaruh yang signifikan, hal tersebut menunjukkan bahwa pentingnya efektivitas pajak hotel terhadap penerimaan pajak daerah. Kontribusi pajak hotel memiliki pengaruh tidak signifikan berarah negatif, artinya jika kotribusi pajak hotel meningkat maka penerimaan pajak daerah tidak serta merta ikut meningkat bisa saja penerimaan pajak daerah nilainya tetap atau menurun. Pengaruh potensi, efektivitas pemungutan dan kontribusi pajak hotel terhadap penerimaan pajak daerah secara simultan memiliki pengaruh yang signifikan dan berarah positif, hal tersebut menandakan jika potensi, efektivitas dan kontribusi pajak hotel harus secara bersama-sama dilakukan untuk memberikan pengaruh terhadap penerimaan pajak daerah di Kabupaten Bandung. Pemerintah daerah dapat mengikut sertakan petugas kecamatan yang ada di Kabupaten Bandung untuk melaporkan potensi pajak hotel yang ada di daerahnya agar dilakukan pemungutan pajak yang dapat mempengaruhi penerimaan pajak daerah.
\end{abstract}

Kata Kunci : Potensi Pajak Hotel, Penerimaan Pajak Daerah

\section{ABSTRACT}

The purpose of this study is to find out how much influence the potential, effectiveness and contribution of hotel taxes on local tax revenue in Bandung Regency partially and simultaneously. Data sources used are primary and secondary data. The method used in this research is descriptive and verification analysis. This research was conducted at the Bandung District Financial Agency. The data taken is 10 years from 2008 to 2017. The analysis technique used is descriptive analysis, Classic Assumption Test, Determination Coefficient, Multiple Correlation Coefficient and Path Analysis. The results of this study that the hotel tax potential has an insignificant influence on local tax revenue, it shows that the potential if not maximized is not affected by local tax revenue. Hotel tax effectiveness has a significant influence, it shows that the importance of hotel tax effectiveness on local tax revenue. The hotel tax contribution has a negatively significant non-significant influence, meaning that if the hotel tax contribution increases, the local tax revenue does not necessarily increase, it can be that the local tax revenue is fixed or decreases. The effect of the potential, effectiveness and contribution of hotel taxes on local tax revenues simultaneously has a significant and positive influence, this indicates that the potential, effectiveness and contribution of hotel taxes must be jointly carried out to influence the 
local tax revenue in Bandung Regency. Local governments can include sub-district officials in Bandung Regency to report hotel tax potential in their area so that tax collection can be done that can affect local tax revenue.

\section{Keyword : Hotel Tax Potential, Regional Tax Revenue}

\section{PENDAHULUAN Latar Belakang}

Dengan diberlakukannya Undang-Undang Otonomi Daerah, dapat mendorong sistem pemerintah daerah menjadi desentralisasi. Hal tersebut berdampak pada pemerintah daerah dalam melakukan tugas, wewenang dan kebijakan dapat diputuskan secara langsung. Kemampuan pemerintah daerah dalam memaksimalkan potensi penerimaan pajak daerah dinilai bahwa penyelenggaraan otonomi daerah tersebut berhasil dilakukan. (Alisman, 2015) (Wati \& Fajar, 2017) (Nurdin \& Riana, 2013). Pendapatan pajak daerah dinilai sangat penting sebagai sumber penerimaan daerah yang bersifat self assessment maupun official assessment yang digunakan untuk mengembangkan wilayahnya sendiri dalam membangun ekonomi daerah, baik secara infrastruktur maupun non infrastruktur. (Bernardin \& Sofyan, 2017)

Berdasarkan Undang-Undang Nomor 28 Tahun 2009 pajak daerah di Indonesia terbagi menjadi dua, yaitu pajak Provinsi dan pajak Kabupaten/Kota. Pajak provinsi terdiri dari lima jenis pajak yaitu Pajak Kendaraan Bermotor, Bea Balik Nama Kendaraan Bermotor, Pajak Bahan Bakar Kendaraan Bermotor, Pajak Air Permukaan, serta Pajak Rokok. Sedangkan untuk pajak Kabupaten/Kota terdiri dari sebelas jenis pajak yaitu Pajak Hotel, Pajak Restoran, Pajak Hiburan, Pajak Reklame, Pajak Penerangan Jalan, Pajak Mineral Bukan Logam dan Batuan, Pajak Parkir, Pajak Air Tanah, Pajak Sarang Burung Walet, Pajak Bumi dan Bangunan Perdesaan dan Perkotaan, serta Bea Perolehan Hak atas Tanah dan Bangunan.

Kabupaten Bandung memiliki tempat wisata berbagai macam dari mulai kawah, pemandian air panas dan pegunungan, sehingga dapat menarik wisatawan untuk berkunjung ke Kabupaten Bandung. Hal ini berdampak pula pada penerimaan pajak hotel di Kabupaten Bandung, semakin banyak wisatawan yang menggunakan fasilitas hotel dapat menambah jumlah penerimaan pajak hotel. Dalam memungut pajak hotel pemerintah daerah Kabupaten Bandung berorientasi pada target yang ditentukan, hal tersebut dapat dilihat bahwa efektivitas pajak hotel selalu efektif pada realisasi penerimaan pajak hotel di Kabupaten Bandung yang selalu meningkat setiap tahunnya.

Namun nilai efektivitas tersebut tidak berarti seluruh penerimaan pajak hotel sudah sesuai dengan potensi yang ada di Kabupaten Bandung, maka penulis merasa perlu untuk meneliti potensi pajak hotel, efektivitas pajak hotel dan kontribusi pajak hotel terhadap penerimaan pajak daerah.

Tujuan dari penelitian ini adalah untuk mengetahui seberapa besar pengaruh potensi, efektivitas, dan kontribusi pajak hotel terhadap penerimaan pajak daerah di Kabupaten Bandung pada tahun 20082017. Maka dapat dirumuskan untuk rumusan penelitian ini yakni bagaimana kondisi potensi pajak hotel, efektivitas pajak hotel, kontribusi pajak hotel dan penerimaan pajak daerah di kabupaten bandung serta pengaruh secara parsial dan simultan antara kondisi potensi pajak hotel, efektivitas pajak hotel, kontribusi pajak hotel dan penerimaan pajak daerah di kabupaten bandung.

\section{TINJAUAN PUSTAKA}

\section{Pajak Daerah}

Pajak daerah menurut (Mardiasmo, 2013) mengemukakan bahwa "pajak daerah adalah kontribusi wajib kepada daerah yang terutang oleh orang pribadi atau badan yang bersifat memaksa berdasarkan Undang-Undang, dengan tidak mendapatkan imbalan secara langsung dan digunakan untuk keperluan daerah bagi sebesar-besarnya kemakmuran rakyat.

Abuyamin dalam Bernardin dan Sofyan (2017:277) menyatakan bahwa "pajak daerah adalah kontribusi wajib pajak daerah yang terutang oleh orang pribadi atau badan yang bersifat memaksa berdasarkan undang-undang dengan tidak mendapatkan imbalan secara langsung dan digunakan untuk keperluan daerah bagi sebesar-besarnya kemakmuran rakyat". Pajak daerah yaitu kontribusi wajib 
pajak orang pribadi atau badan yang kepada pemerintah daerah yang digunakan untuk kesejahteraan masyarakat daerah tersebut dengan sifat memaksa sesuai dengan peraturan undang-undang yang berlaku.

\section{Jenis Pajak Daerah}

Berdasarkan Undang-Undang Nomor 28 Tahun 2009, jenis pajak daerah yaitu: (1) Pajak Provinsi meliputi Pajak Kendaraan Bermotor, Bea Balik Nama Kendaraan Bermotor, Pajak Bahan Bakar Kendaraan Bermotor, Pajak Air Permukaan, serta Pajak Rokok. (2) Pajak Kabupaten/Kota meliputi Pajak Hotel, Pajak Restoran, Pajak Hiburan, Pajak Reklame, Pajak Penerangan Jalan, Pajak Mineral Bukan Logam dan Batuan, Pajak Parkir, Pajak Air Tanah, Pajak Sarang Burung Walet, Pajak Bumi dan Bangunan Perdesaan dan Perkotaan, serta Bea Perolehan Hak atas Tanah dan Bangunan.

\section{Pajak Hotel}

Sesuai dengan Undang-Undang Nomor 28 Tahun 2009 Pasal 1 angka 20 dan 21, pajak hotel adalah pajak daerah atas pelayanan yang disediakan oleh hotel. Sedangkan yang dimaksud dengan hotel adalah fasilitas penyedia jasa penginapan/peristirahatan termasuk jasa terkait lainnya dengan dipungut bayaran, yang mencakup juga motel, losmen, gubuk pariwisata, wisma pariwisata, pesanggrahan, rumah penginapan dan sejenisnya, serta rumah kos dengan jumlah kamar lebih dari 10 (sepuluh).

\section{Dasar Hukum Pemungutan Pajak Hotel}

Menurut Marihot dalam (Felychita Shanza D. A. P. \& Pratomo, 2015), pemungutan pajak hotel di Indonesia saat ini di dasarkan pada dasar hukum yang jelas dan kuat sehingga harus dipatuhi oleh masyarakat dan pihak terkait. Adapun dasar hukum tentang pajak hotel antara lain: (1) UndangUndang Nomor 34 Tahun 2000 yang merupakan perubahan atas Undang-Undang Nomor 18 Tahun 1997 tentang pajak daerah dan reteribusi daerah. (2) Peraturan Pemerintah Nomor 65 Tahun 2001 tentang pajak daerah. (3) Peraturan daerah kabupaten/kota yang mengatur tentang pajak hotel, Keputusan bupati/walikota yang mengatur tentang pajak hotel sebagai aturan pelaksanaan peraturan daerah tentang pajak hotel pada kabupaten/kota dimaksud.

\section{Obyek, Subyek dan Wajib Pajak Hotel}

Menurut Peraturan Daerah Kabupaten Bandung Nomor 6 Tahun 2016 menambahkan bahwa objek pajak hotel antara lain fasilitas olahraga dan hiburan terdiri dari pusat kebugaran, kolam renang, tenis, karaoke, pub, dan/atau diskotik yang disediakan atau dikelola hotel. Menurut Undang-Undang Nomor 28 Tahun 2009, subjek pajak hotel adalah orang pribadi atau badan yang melakukan pembayaran kepada orang pribadi atau badan yang mengusahakan Hotel. Sedangkan wajib pajak hotel adalah orang pribadi atau badan yang mengusahakan hotel.

\section{Potensi Pajak Hotel}

Menurut Rahmanto dalam (Sugiarto, Danurdara, \& Rofi, 2015) mengemukakan bahwa "potensi pajak hotel dapat diukur berdasar pada data jumlah kamar tiap hotel, tarif rata-rata dan tingkat hunian hotel. Selanjutnya dari potensi yang dicapai dan berdasarkan data realisasi penerimaan pajak hotel maka akan dapat diketahui efektifitas dari pajak hotel". Sedangkan pengertian lainnya menurut Mardiasmo dan Makhfatih dalam (Felychita Shanza D. A. P. \& Pratomo, 2015) berpendapat bahwa "potensi pajak merupakan hasil temuan pendataan di lapangan yang berkaitan jumlah serta frekuensi obyek pajak yang kemudian dikalikan dengan tarif dasar pajak". Sehingga pemaksimalan dalam potensi pajak hotel diharapkan menjadi factor dalam peningkatan sumber dari penerimaan.

\section{Efektivitas Pajak Hotel}

Menurut (Sutama, Syafruddin, \& Zulfiana, 2017), berpendapat bahwa "efektivitas yaitu seberapa jauh tercapainya suatu target yang telah ditentukan sebelumnya". Sedangkan "efektivitas pajak daerah menunjukkan kemampuan pemerintah daerah dalam mengumpulkan pajak daerah sesuai dengan jumlah penerimaan pajak daerah yang ditargetkan". Menurut Peraturan Menteri Dalam Negeri Nomor 13 Tahun 2006 tentang Pedoman Pengelolaan Keuangan Daerah, efektif merupakan pencapaian hasil program dengan target yang telah ditetapkan, yaitu dengan cara membandingkan keluaran dengan 
hasil. Keefektifan mencapai target yang dituangkan dalam realisasi sangat menentukan dalam penentuan efiktif atau tidaknya pajak hotel yang diterima.

\section{Kontribusi Pajak Hotel}

Menurut (Tundoong \& Karamoy, 2015) berpendapat bahwa kontribusi digunakan untuk mengetahui sejauh mana pajak daerah memberikan sumbangan dalam penerimaan pendapatan daerah. Dalam mengetahui kontribusi dilakukan dengan membandingkan penerimaan pajak daerah (khususnya pajak hotel) periode tertentu dengan penerimaan pendapatan daerah periode tertentu pula. Semakin besar hasilnya berarti semakin besar pula peranan pajak daerah terhadap pendapatan daerah, begitu pula sebaliknya.

\section{METODE PENELITIAN}

\section{Desain Penelitian}

Metode penelitian yang digunakan adalah deskriptif verifikatif dengan pendekatan kuantitaif. Sumber data yang digunakan pada penelitian ini yaitu data primer dan sekunder. Data primer penelitian ini berasal dari pihak Badan Keuangan Daerah Kabupaten Bandung dan data sekunder berasal dari hasil publikasi Badan Keuangan Daerah Kabupaten Bandung dan Badan Pusat Statistika Kabupaten Bandung. Populasi dalam penelitian ini adalah seluruh data hotel dan laporan penerimaan pajak daerah pada Badan Keuangan Daerah Kabupaten Bandung. Sedangkan sampel dalam penelitian ini adalah data jumlah hotel, kamar hotel, tarif hotel serta laporan target dan realisasi pajak hotel dan seluruh pajak daerah Kabupaten Bandung selama 10 tahun 2008-2017.Pada penelitian ini, penulis menggunakan analisis data yang digunakan adalah analisis jalur (path analysis).

\section{HASIL PENELITIAN DAN PEMBAHASAN ANALISIS DESKRIPTIF}

Pada penelitian ini potensi, efektivitas dan kontribusi pajak hotel terhadap penerimaan pajak daerah di Kabupaten Bandung periode 2008-2017, memperoleh data dari Badan Keuangan Daerah Kabupaten Bandung dan Badan Pusat Statistika Kabupaten Bandung, berikut rincian data pertahunnya:

\begin{tabular}{cc}
\multicolumn{2}{c}{ Tabel 1. Potensi Pajak Hotel } \\
\hline Tahun & $\begin{array}{c}\text { Total Potensi Pajak } \\
\text { Hotel }\end{array}$ \\
\hline $2008^{*}$ & $31,743,660,227$ \\
2009 & $14,415,009,496$ \\
2010 & $10,992,700,292$ \\
2011 & $15,624,271,833$ \\
2012 & $18,122,443,085$ \\
2013 & $23,575,804,389$ \\
2014 & $33,220,317,612$ \\
2015 & $40,593,005,172$ \\
2016 & $40,440,909,198$ \\
2017 & $42,571,160,669$ \\
\hline Sumber: BKD dan BPS, diolah
\end{tabular}

Perubahan nilai pada variabel potensi pajak di Kabupaten Bandung periode 2008-2017 setiap tahunnya mengalami peningkatan hanya pada tahun 2009 dan 2010 yang mengalami penurunan hal tersebut dipengaruhi oleh banyaknya jumlah kamar hotel yang berkurang baik hotel berbintang maupun nonbintang serta nilai rata-rata tarif kamar hotelnya.

Tabel 2. Efektivitas Pajak Hotel 


\begin{tabular}{cc}
\hline TAHUN & $\begin{array}{c}\text { EFEKTIVITAS } \\
\text { PEMUNGUTAN PAJAK } \\
\text { HOTEL }\end{array}$ \\
\hline 2008 & $2 \%$ \\
2009 & $3 \%$ \\
2010 & $10 \%$ \\
2011 & $9 \%$ \\
2012 & $13 \%$ \\
2013 & $10 \%$ \\
2014 & $9 \%$ \\
2015 & $8 \%$ \\
2016 & $10 \%$ \\
2017 & $12 \%$ \\
\hline Sumber: BKD dan BPS, diolah
\end{tabular}

Perubahan nilai pada variabel efektivitas pajak hotel memiliki nilai yang tidak tetap, kecenderungan selalu naik dan turun. Hal tersebut disebabkan oleh jumlah penerimaan pajak hotel yang mengalami penurunan serta kenaikan yang signifikan dan tidak dan jumlah potensi pajak hotel yang selalu meningkat maka berdampak pada nilai efektivitasnya.

Tabel 3. Kontribusi Pajak Hotel

\begin{tabular}{rc} 
TAHUN & KONTRIBUSI \\
\hline 2008 & $1.01 \%$ \\
2009 & $1.00 \%$ \\
2010 & $1.89 \%$ \\
2011 & $1.00 \%$ \\
2012 & $1.24 \%$ \\
2013 & $0.83 \%$ \\
2014 & $1.06 \%$ \\
2015 & $0.93 \%$ \\
2016 & $1.10 \%$ \\
2017 & $1.11 \%$ \\
\hline Sumber: BKD, diolah
\end{tabular}

Nilai variabel kontribusi pajak hotel setiap tahunnya memiliki nilai yang tidak tetap, cenderung selalu meningkat dan menurun hal tersebut dipengaruhi oleh jumlah penerimaan pajak hotel dan penerimaan pajak daerah yang selalu meningkat dan menurun.

Tabel 4. Penerimaan Pajak Hotel dan Pajak Daerah

\begin{tabular}{ccc}
\hline TAHUN & PAJAK HOTEL & $\begin{array}{c}\text { PAJAK } \\
\text { DAERAH }\end{array}$ \\
\hline 2008 & $521,130,208$ & $51,654,333,710$ \\
2009 & $481,269,352$ & $47,951,110,528$ \\
2010 & $1,122,094,256$ & $59,385,578,062$ \\
2011 & $1,382,279,874$ & $137,799,240,880$ \\
2012 & $2,311,227,053$ & $186,141,858,448$ \\
2013 & $2,400,777,599$ & $287,766,327,300$ \\
2014 & $3,152,714,621$ & $298,589,031,518$ \\
2015 & $3,167,347,791$ & $340,007,248,935$
\end{tabular}




\begin{tabular}{crr}
2016 & $4,203,833,353$ & $384,495,956,018$ \\
2017 & $5,177,530,605$ & $465,249,439,944$ \\
\hline \multirow{2}{*}{ Sumber: BKD, diolah }
\end{tabular}

Dapat dilihat pada tabel 4 bahwa nilai penerimaan pajak hotel dan pajak daerah setiap tahunnya selalu peningkatan hanya pada tahun 2009 saja yang mengalami penurunan.

\section{ANALISIS VERIFIKATIF}

Pada penelitian potensi, efektivitas dan kontribusi pajak hotel terhadap penerimaan pajak daerah di Kabupaten Bandung periode 2008-2017, penulis menggunakan uji asumsi klasik, uji koefisien korelasi, uji koefisien determinasi, uji analisis jalur dan uji hipotesis. Pengujian tersebut dibantu oleh program SPSS versi 21. Berikut merupakan penjelasan terkait uji yang dilakukan oleh peneliti:

1. UJI ASUMSI KLASIK

a. Uji Normalitas

Tabel 5. Hasil uji normalitas

One-Sample Kolmogorov-Smirnov Test

\begin{tabular}{rcr}
\hline & & $\begin{array}{r}\text { Unstandardize } \\
\text { d Residual }\end{array}$ \\
\hline Normal Parameters ${ }^{\mathrm{a}, \mathrm{b}}$ & Mean & 10 \\
& Std. Deviation & .0000000 \\
Most Extreme Differences & Absolute & .117 \\
& Positive & .117 \\
Kolmogorov-Smirnov Z & -.115 \\
Asymp. Sig. (2-tailed) & .370 \\
\hline
\end{tabular}

a. Test distribution is Normal.

b. Calculated from data.

Dari data tersebut dapat dilihat nilai asymp.sig 0,999 > nilai signifikan 0,05 maka dapat disimpulkan bahwa dalam penelitian ini memiliki nilai berdistribusi normal.

b. Uji Autokorelasi

Tabel 6. Hasil uji autokorelasi

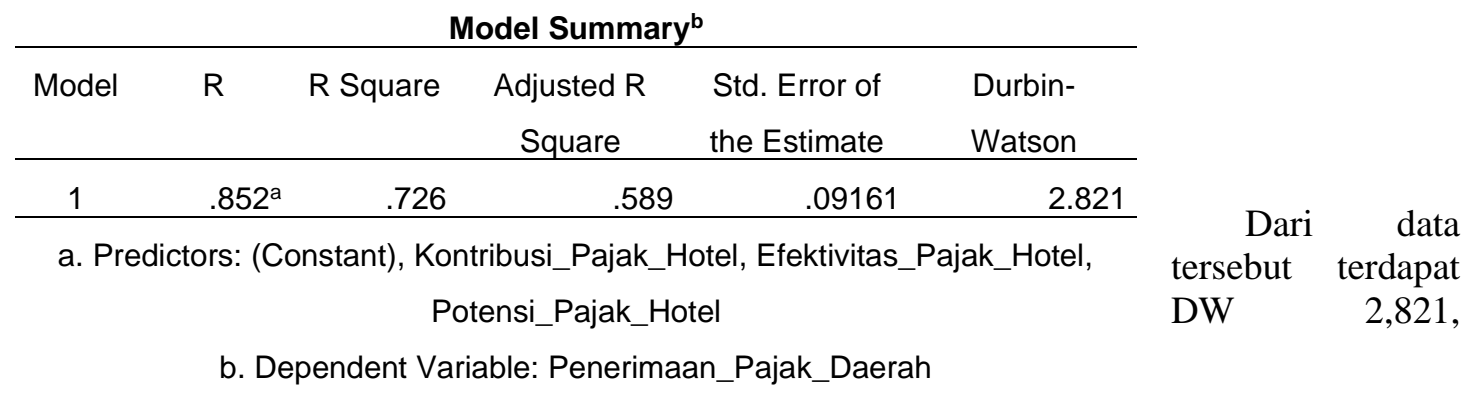


nilainya lebih dari angka 1 dan tidak lebih dari angka 3 maka dapat disimpulkan bahwa penelitian ini tidak terjadi autokorelasi.

c. Uji heteroskedastisitas

Tabel 7. Hasil uji heteroskedastisitas

\begin{tabular}{|c|c|c|c|c|c|c|c|}
\hline \multicolumn{8}{|c|}{ Coefficients $^{a}$} \\
\hline \multirow{2}{*}{\multicolumn{2}{|c|}{ Model }} & \multicolumn{2}{|c|}{ Unstandardized Coefficients } & \multirow{2}{*}{\multicolumn{2}{|c|}{$\begin{array}{c}\text { Standardized Coefficients } \\
\text { Beta }\end{array}$}} & \multirow[t]{2}{*}{$\mathrm{t}$} & \multirow[t]{2}{*}{ Sig. } \\
\hline & & B & Std. Error & & & & \\
\hline \multirow{4}{*}{1} & (Constant) & 1.396 & .674 & & & 2.071 & .084 \\
\hline & Potensi_Pajak_Hotel & -.050 & .027 & & -.515 & -1.818 & .119 \\
\hline & Efektivitas_Pajak_Hotel & -.602 & .323 & & -.458 & -1.865 & .111 \\
\hline & Kontribusi Pajak Hotel & -9.126 & 4.183 & & -.621 & -2.181 & .072 \\
\hline
\end{tabular}

a. Dependent Variable: RES2

Dari data tersebut dapat dilihat bahwa nilai signifikansi variabel potensi, efektivitas dan kontribusi pajak hotel memiliki nilai > 0,05 maka dapat disimpulkan bahwa penelitian ini tidak terjadi heteroskedastisitas.

d. Uji multikolinearitas

Tabel 8. Hasil uji multikoliearitas

\begin{tabular}{|c|c|c|c|}
\hline \multicolumn{2}{|c|}{ Model } & \multicolumn{2}{c|}{ Coeffinearity Statistics } \\
\cline { 2 - 4 } \multicolumn{2}{|c|}{} & Tolerance & VIF \\
\hline \multirow{3}{*}{1} & (Constant) & & \\
\cline { 2 - 4 } & Potensi_Pajak_Hotel & .706 & 1.417 \\
\cline { 2 - 4 } & Efektivitas_Pajak_Hotel & .940 & 1.064 \\
\cline { 2 - 4 } & Kontribusi_Pajak_Hotel & .699 & 1.430 \\
\hline
\end{tabular}

a. Dependent Variable: Penerimaan_Pajak_Daerah

Dari data tersebut dapat dilihat nilai toleransi seluruh variabel diatas $>$ dari nilai signifikansi 0,01 dan nilai VIF tidak melebihi 10. Maka dapat disimpulkan bahwa penelitian ini tidak terjadi multikolinearitas.

2. Koefisien determinasi

Tabel 10. Hasil uji koefisien determinasi

\begin{tabular}{|c|c|c|c|c|}
\hline \multicolumn{5}{|c|}{ Model Summary } \\
\hline Model & $\mathrm{R}$ & R Square & Adjusted R Square & Std. Error of the Estimate \\
\hline 1 & $.857^{\mathrm{a}}$ & .734 & .601 & .09027 \\
\hline
\end{tabular}

a. Predictors: (Constant), Kontribusi Pajak Hotel, Efektifitas Pajak Hotel, Potensi Pajak Hotel

Dari data tersebut dapat dilihat nilai koefisien determinasi $\mathrm{R}$ square sebesar 0,734 atau $73,4 \%$ nilai pengaruh potensi, efektivitas dan kontribusi pajak hotel secara simultan memiliki hubungan yang kuat. 
3. Analisis jalur (Path analysis)



Sumber: Hasil olahan penulis

Gambar 1. Hasil Analisis Jalur

Dari gambar 1. Dapat diketahui pengaruh langsung dan tidak langsung dari variabel yang diteliti. Berikut hasil perhitungannya:

a. Pengaruh langsung potensi pajak hotel terhadap penerimaan pajak daerah

$=\rho \mathrm{yx}_{1}$. $\rho \mathrm{yx}_{1}$

$=0,410 \times 0,410=0,168$ atau $16,8 \%$

Pengaruh tidak langsung potensi pajak hotel terhadap penerimaan pajak daerah melalui efektivitas pemungutan pajak hotel

$=\rho \mathrm{yx}_{1} \cdot \mathrm{rx}_{1} \mathrm{x}_{2} . \rho \mathrm{yx}_{2}$

$=0,410 \times 0,102 \times 0,922=0,038$ atau $3,8 \%$

b. Pengaruh langsung efektivitas pemungutan pajak hotel terhadap penerimaan pajak daerah

$=\rho \mathrm{yx}_{2} . \rho \mathrm{yx}_{2}$

$=0,922 \times 0,922=0,850$ atau $85 \%$

Pengaruh tidak langsung efektivitas pemungutan pajak hotel terhadap penerimaan pajak daerah melalui kontribusi pajak hotel $=\rho \mathrm{yx}_{2} . \mathrm{rx}_{2} \mathrm{x}_{3}$. $\rho \mathrm{yx}_{3}$

$$
\begin{aligned}
& =0,922 \times 0,139 \times(-0,795) \\
& =-0,102 \text { atau }-10,2 \%
\end{aligned}
$$

c. Pengaruh langsung kontribusi pajak hotel terhadap penerimaan pajak daerah

$=\rho \mathrm{yx}_{3} . \rho \mathrm{yx}_{3}$

$=(-0,795) \times(-0,795)=0,632$ atau $63,2 \%$

Pengaruh tidak langsung kontribusi pajak hotel terhadap penerimaan pajak daerah melalui potensi pajak hotel

$$
\begin{aligned}
& =\rho \mathrm{yx}_{3 .} \mathrm{rx}_{1} \mathrm{x}_{3 .} \rho \mathrm{yx}_{1} \\
& =(-0,795) \times(-0,513) \times 0,410 \\
& =0,167 \text { atau } 16,7 \%
\end{aligned}
$$

\begin{tabular}{|c|c|c|c|c|c|c|}
\hline \multirow{2}{*}{\multicolumn{2}{|c|}{ Model }} & \multicolumn{2}{|c|}{ Unstandardized Coefficients } & \multirow{2}{*}{$\begin{array}{c}\text { Standardized Coefficients } \\
\text { Beta }\end{array}$} & \multirow[t]{2}{*}{$\mathrm{t}$} & \multirow[t]{2}{*}{ Sig. } \\
\hline & & B & Std. Error & & & \\
\hline \multirow{4}{*}{1} & (Constant) & -.295 & 1.871 & & -.158 & .880 \\
\hline & Potensi Pajak Hotel & .061 & .075 & .209 & .804 & .452 \\
\hline & Efektifitas Pajak Hotel & 2.387 & .873 & .590 & 2.734 & .034 \\
\hline & Kontribusi Pajak Hotel & -24.210 & 11.855 & -.536 & -2.042 & .087 \\
\hline
\end{tabular}

4. Hasil Uji Hipotesis

Tabel 11. Hasil uji T

\section{Coefficients $^{\mathrm{a}}$}

a. Dependent Variable: Penerimaan Pajak Daerah 


\section{Hasil Pengujian secara Parsial}

a. Dapat dilihat pada tabel 11 nilai standardized coefficients Beta variabel potensi memiliki pengaruh terhadap penerimaan pajak daerah sebesar 0,209 atau 20,9\%. Dengan nilai $t_{\text {hitung }}$ lebih kecil dari $\mathrm{t}_{\text {tabel }}(0,804<2,365)$ dengan nilai signifikan $0,452>0,05$. Hal ini artinya bahwa potensi pajak hotel secara parsial berpengaruh tidak signifikan terhadap penerimaan pajak daerah Kabupaten Bandung.

b. Dapat dilihat pada tabel 11 nilai standardized coefficients Beta variabel efektivitas memiliki pengaruh terhadap penerimaan pajak daerah sebesar 0,590 atau 59\%. Dengan nilai $\mathrm{t}_{\text {hitung }}$ lebih besar dari $t_{\text {tabel }}(2,734>2,365)$ dengan nilai signifikan $0,034<0,05$. Hal ini artinya bahwa efektivitas pajak hotel secara parsial berpengaruh signifikan terhadap penerimaan pajak daerah Kabupaten Bandung.

c. Dapat dilihat pada tabel 11 nilai standardized coefficients Beta variabel kontribusi memiliki pengaruh terhadap penerimaan pajak daerah sebesar $-0,536$ atau $-53,6 \%$. Dengan nilai $t_{\text {hitung }}$ lebih kecil dari tabel $(-2,042<2,365)$ dengan nilai signifikan $0,087>0,05$. Hal ini artinya bahwa kontribusi pajak hotel secara parsial berpengaruh tidak signifikan terhadap penerimaan pajak daerah Kabupaten Bandung.

Hasil pengujian secara Simultan

Tabel 12. Hasil uji simultan

\begin{tabular}{|c|c|c|c|c|c|c|}
\hline & \multicolumn{6}{|c|}{ ANOVA $^{a}$} \\
\hline & Model & Sum of Squares & Df & Mean Square & $\mathrm{F}$ & Sig. \\
\hline & Regression & .135 & 3 & .045 & 5.519 & $.037^{b}$ \\
\hline 1 & Residual & .049 & 6 & .008 & & \\
\hline & Total & .184 & 9 & & & \\
\hline
\end{tabular}

a. Dependent Variable: Penerimaan Pajak Daerah

b. Predictors: (Constant), Kontribusi Pajak Hotel, Efektifitas Pajak Hotel, Potensi Pajak Hotel

Dari data tersebut memperoleh hasil dari perbandingan $\mathrm{F}_{\text {hitung }}$ lebih besar dari $\mathrm{F}_{\text {tabel }}$ yakni 5,519 > 4,76, dengan nilai signifikansi 0,037 < 0,05 maka dapat disimpulkan bahwa secara simultan potensi pajak hotel, efektivitas pajak hotel dan kontribusi pajak hotel berpengaruh signifikan terhadap penerimaan pajak daerah.

\section{PEMBAHASAN}

\section{Pengaruh Potensi Pajak Hotel (X1) terhadap Penerimaan Pajak Daerah secara Parsial}

Berdasarkan dari hasil uji $\mathrm{T}$ pada tabel 11 . Hasil variabel potensi memiliki pengaruh terhadap penerimaan pajak daerah sebesar 0,209 atau 20,9\%. Dengan nilai thitung lebih kecil dari tabel $(0,804<$ 2,365 ) dengan nilai signifikan $0,452>0,05$ berarah positif. Hal ini artinya bahwa potensi pajak hotel secara parsial berpengaruh tidak signifikan terhadap penerimaan pajak daerah Kabupaten Bandung.

Dari hasil tersebut menggambarkan ketika potensi pajak hotel meningkat maka nilai penerimaan pajak tidak serta merta meningkat bisa saja tetap, hal tersebut karena besarnya nilai potensi tidak berpengaruh pada penerimaan pajak daerah jika tidak tergali dan tidak terpungut hutang pajaknya.

\section{Pengaruh Efektivitas Pajak Hotel $\left(\mathbf{X}_{2}\right)$ terhadap Penerimaan Pajak Daerah secara Parsial}

Berdasarkan dari hasil uji $\mathrm{T}$ pada tabel 11. variabel efektivitas memiliki pengaruh terhadap penerimaan pajak daerah sebesar 0,590 atau 59\%. Dengan nilai $t_{\text {hitung }}$ lebih besar dari $t_{\text {tabel }}(2,734>$ $2,365)$ dengan nilai signifikan $0,034<0,05$ berarah positif. Hal ini artinya bahwa efektivitas pajak hotel secara parsial berpengaruh signifikan terhadap penerimaan pajak daerah Kabupaten Bandung.

Dari hasil tersebut menggambarkan ketika efektivitas pajak hotel meningkat maka penerimaan pajak daerah meningkat. Perolehan hasil tersebut sesuai dengan nilai realisasi penerimaan pajak hotel yang sejalan dan searah dengan penerimaan pajak daerah yang selalu meningkat setiap tahunnya. 


\section{Pengaruh Kontribusi Pajak Hotel $\left(\mathbf{X}_{3}\right)$ terhadap Penerimaan Pajak Daerah secara Parsial}

Berdasarkan dari hasil uji $\mathrm{T}$ pada tabel 11. Hasil variabel kontribusi memiliki pengaruh terhadap penerimaan pajak daerah sebesar $-0,536$ atau $-53,6 \%$. Dengan nilai $t_{\text {hitung }}$ lebih kecil dari $t_{\text {tabel }}(-2,042<$ $2,365)$ dengan nilai signifikan $0,087>0,05$ berarah negatif. Hal ini artinya bahwa kontribusi pajak hotel secara parsial berpengaruh tidak signifikan terhadap penerimaan pajak daerah Kabupaten Bandung.

Dari hasil tersebut menggambarkan ketika kontribusi pajak hotel meningkat maka nilai penerimaan pajak daerah mengalami penurunan, hal tersebut dilihat dari nilai kontribusi pajak hotel yang selalu mengalami kecenderungan naik turun dan nilai kontribusinya tidak melebih 5\% setiap tahunnya.

\section{Pengaruh Potensi Pajak Hotel $\left(\mathbf{X}_{1}\right)$, Efektivitas Pajak Hotel $\left(\mathbf{X}_{2}\right)$, dan Kontribusi Pajak Hotel ( $\left.\mathbf{X}_{3}\right)$ terhadap Penerimaan Pajak Daerah secara Simultan}

Berdasarkan dari hasil Uji F pada tabel 12. Hasil dari data tersebut memiliki nilai perbandingan $F_{\text {hitung }}$ lebih besar dari $\mathrm{F}_{\text {tabel }}$ yakni 5,519 > 4,76, dengan nilai signifikansi 0,037 < 0,05 maka dapat disimpulkan bahwa secara simultan potensi pajak hotel, efektivitas pajak hotel dan kontribusi pajak hotel berpengaruh signifikan terhadap penerimaan pajak daerah.

Dari hasil diatas, pengaruh potensi pajak hotel, efektivitas pajak hotel dan kontribusi pajak hotel terhadap penerimaan pajak daerah sebesar $73,4 \%$ dan sisanya $26,6 \%$ faktor lain yang tidak diteliti pada penelitian ini. Dengan nilai tersebut pengaruh yang kuat apabila potensi pajak hotel, efektivitas pajak hotel dan kontribusi pajak hotel secara bersama-sama meningkat sehingga dapat meningkatkan penerimaan pajak daerah. Berdasarkan hasil penelitian dan perhitungan, efektivitas pajak hotel memiliki pengaruh dominan dibandingkan potensi pajak hotel dan kontribusi pajak hotel, hal ini dikarenakan besarnya nilai efektivitas yang tinggi dapat mempengaruhi penerimaan pajak daerah di Kabupaten Bandung.

\section{SIMPULAN}

Berdasarkan hasil penelitian dan pembahasan variabel potensi pajak hotel, efektivitas pajak hotel dan kontribusi pajak hotel terhadap penerimaan pajak daerah di Kabupaten Bandung, maka dapat ditarik kesimpulan sebagai berikut:

Keadaan penerimaan pajak daerah searah dan sejalan dengan penerimaan pajak hotel yang selalu meningkat setiap tahunnya, hal tersebut dipengaruhi oleh besarnya nilai efektivitas pemungutan pajak hotel, serta potensi dan kontribusi yang memiliki nilai kecenderungan meningkat.

Potensi pajak hotel memiliki pengaruh tidak signifikan terhadap penerimaan pajak daerah. Hal tersebut menandakan bahwa besarnya nilai potensi tidak terlalu berpengaruh terhadap nilai penerimaan pajak daerah. Efektivitas pajak hotel memiliki pengaruh yang signifikan terhadap penerimaan pajak daerah. Hal tersebut sejalan dengan penerimaan pajak hotel yang selalu meningkat setiap tahunnya. Kontribusi pajak hotel memiliki pengaruh yang tidak signifikan berarah negatif terhadap penerimaan pajak daerah. Hal tersebut menandakan ketika penerimaan pajak daerah meningkat maka kontribusi pajak hotel menurun. Hasil tersebut diperkuat dengan nilai kontribusi pajak hotel yang kecil dibanding dengan kontribusi pajak daerah lainnya. Pengaruh potensi pajak hotel, efektivitas pajak hotel dan kontribusi pajak hotel terhadap penerimaan pajak daerah secara simultan memiliki pengaruh yang signifikan. Dari hasil tersebut menandakan bahwa potensi pajak hotel, efektivitas pajak hotel dan kontribusi pajak hotel harus dilakukan bersama-sama agar mempengaruhi besarnya nilai penerimaan pajak daerah di Kabupaten Bandung. Berdasarkan hasil perhitungan, variabel efektivitas dinilai lebih dominan dibanding variabel lain.

\section{REFERENSI}

Alisman. (2015). Analisis Faktor-Faktor yang Mempengaruhi Penerimaan Pajak Hotel di Kabupaten

Aceh Barat. Jurnal Ekonomi Dan Kebijakan Publik Indonesia, 2(1), 1-13.

Badan Pusat Statistik. (2008-2017) Kabupaten Bandung Dalam Angka 
Bernardin, D. E. Y., \& Sofyan, I. (2017). Penerimaan Pajak Daerah Melalui Kontribusi Pajak Hotel dan Hiburan. Ekspansi, Vol. 9 No.(2), 275-289.

Felychita Shanza D. A. P., \& Pratomo, D. (2015). ANALISIS POTENSI , EFEKTIVITAS PEMUNGUTAN DAN UPAYA PAJAK ( TAX EFFORT ) HOTEL TERHADAP PENERIMAAN PAJAK DAERAH ( Studi Kasus Pada Dinas Pendapatan Dan Pengelolaan Keuangan Kabupaten Bandung Tahun Anggaran 2007-2013 ). E-Proceeding of Management, 2(1), 539-554.

Mardiasmo. (2013). Perpajakan Edisi Revisi. Yogyakarta: Andi Offset.

Melalui, A., \& Dan, O. (2017). Ekspansi P ENERIMAAN P AJAK D AERAH MELALUI. 9(2), 275289.

Nurdin, S., \& Riana, D. (2013). Analisis Perbandingan Penerimaan PKB Sebelum dan Sesudah Penerapan Tarif Progresif dan Pengaruhnya Terhadap Penerimaan BBNKB. Ecodemica, 1(2), 114.

Peraturan Daerah Kabupaten Bandung Nomor 6 Tahun 2016 tentang Objek Pajak Hotel.

Republik Indonesia. Undang-Undang Nomor 28 tahun 2009 Tentang Pajak Daerah dan Restribusi Daerah.

Republik Indonesia. Undang-Undang Nomor 28 tahun 2007 Tentang Ketentuan Umum dan Tata Cara Perpajakan (KUP).

Republik Indonesia. Undang-Undang No.17 Tahun 2003 pasal 1 dan pasal 11 ayat 3 tentang Keuangan Negara

Republik Indonesia. Undang-Undang No.28 Tahun 2009 pasal 1 angka 20 dan 21 tentang Pajak Hotel

Republik Indonesia. Undang-Undang No.6 Tahun 1983 Tentang Ketentuan Umum dan Tata Cara Perpajakan.

Sugiarto, Y., Danurdara, A. B., \& Rofi, N. (2015). Analisis Potensi Penerimaan Pajak Hotel di Kabupaten Pemalang Jawa Tengah. Barista, 2(1), 47-61.

Sugiyono. (2014). Metode Penelitian Kombinasi (Mixed Methods). Bandung: Alfabeta.

Sutama, I. N., Syafruddin, \& Zulfiana, Y. (2017). Analisis Efisiensi, Efektivitas, dan Kontribusi Pajak Hotel dan Restoran Terhadap Pendapatan Asli Daerah di Kabupaten Sumbawa Barat. Jurnal Ekonomi Dan Bisnis, 14(3), 256-272.

Tundoong, G. K., \& Karamoy, H. (2015). Analisis Efektivitas Penerimaan Pajak Hotel dan Kontribusinya Terhadap Pajak Daerah di Kotamobagu. EMBA, 3(2), 1032-1040.

Wati, M. R., \& Fajar, C. M. (2017). Pengaruh pendapatan asli daerah, dana alokasi umum, dana alokasi khusus, dan dana perimbangan terhadap belanja daerah. Jurnal Kajian Akuntansi, 1(1), 63-76. https://doi.org/10.29264/jinv.v14i1.3546

Copyright (c) 2020 Deden Edwar Yokeu Bernadin, Mega Muliawati Pertiwi 